\title{
Attention to oropharingeal dysfunction in home care: speech therapy management. Appearance and content validation study of a guidance manual
}

Karina de Fatima Portela de Oliveira Pereira(1) Adriano de Souza Pereira(1) Bianca Simone Zeigelboim(1) Rosane Sampaio Santos ${ }^{(1)}$

1) Universidade Tuiuti do Paraná, Curitiba, Paraná, Brasil.

Conflict of interests: Nonexistent

\section{(c)}

Received on: March 28, 2018

Accepted on: August 23, 2018

Corresponding address:

Karina de Fatima Portela de Oliveira Pereira

Rua Jose Bajerski, 921, sobrado 86

CEP: 82220-320 - Curitiba, Paraná, Brasil

E-mail: kari.portela@gmail.com

\section{ABSTRACT}

Purpose: to validate as to appearance and content, the «guidance manual for adult patients with dysphagia in home care speech therapy».

Methods: a qualitative and quantitative study, divided into three stages; first, the pilot material was constructed; second, 8 expert judges, with a master or doctorate degree, were chosen to assess the manual through a questionnaire; and third, 8 caregiver judges of home care patients were chosen to represent the study population.

Results: Pearson's linear correlation was used in the analysis of the judges' answers, considering the responses with a correlation greater than 0,6 which is a parameter that indicates a strong linear correlation.

Conclusion: the results found, after the judges' evaluation, showed a strong correlation between the questions regarding the content of the manual and suggesting appearance and content validity.

Keywords: Home Nursing; Validation Studies; Speech, Language and Hearing Sciences; Deglutition Disorders 


\section{INTRODUCTION}

Home care consists on a range of services performed at home and designed to therapeutic support of the patient. The objectives of this care involves humanized and integral assistance with health education support andincrease life quality of patients in a family environment.

It's a current tendency to offer health care services at home, including Speech Therapy, which has an effective participation, although there is still little material in literature regarding this participation. In practice, there is no specific criteria and guidelines for speech therapist actions in the evaluation process and family orientation of dysphagia patients, especially those attended at home.

The hypothesis for the research development was a creation of a guiding manual about home care attendance to contribute positively in patient management, and yet enables the speech therapist on dysphasic adult patient care, helping on patient evaluation and family and/or caregiver training.

Home care involves actions directed to health, diseases prevention with assistance developed at home, and various medical modalities. It includes outpatient activities, scheduled and continued with preventive and / or assistance actions by the multidisciplinary team 1 .

Caring for the patient's health at home brings improvements to the treatment and greater care capacity of the public network. It aims to reduce costs in the area as an excellent alternative. In $\mathrm{HC}$ the specialized multidisciplinary team interacts for the promotion, maintenance and / or restoration of the patient's health, their functions adaptationin order to reestablish their independence and preserve their autonomy².

In Brazil, "assistênciadomiciliar" (AD) is a health care modality formed by a team of nurses, physiotherapists, doctors, nursing technicians, speech therapists, nutritionists, psychologists and occupational therapists, with the purpose of effecting patient hospitalization at home, called home care ${ }^{3}$. The contribution of AD aims to attempt the modalities demand with the program, and reinforces the importance of educational actions and the speech therapist's role in dysphagia patient rehabilitation with guidelines to all participants ${ }^{4}$.

Resolution CFFa. No. 356/20085, establishes the technical and legal competence of the Speech Therapist to operate in oropharyngeal dysphagia, evaluate and rehabilitate speech, swallowing and language disorders, attending to the patient in family life, while Resolution CFFa. № 382/2010', recognizes dysphagia specialty and emphasizes the work of the speech therapist in the area, who, after evaluating the patient, should trace the speech-language actions.

Rehabilitate dysphagic condition means to work aiming swallowing without risk of complications, considering that the rehabilitation purpose is to restore nutritional conditions, reduces the risk of laryngotracheal aspiration and other complications ${ }^{7}$. Before therapy itself, the speech therapist, family, and patient should discuss and clarify the reason of the treatment and agree to the procedures planned by the speech therapist. It is possible that family members may resist to the treatment and intervention of home care professionals in the residence, therefore, communication and procedure learning is significant and requires from the team efficiency and competence in orientation ${ }^{8}$

The general objective of this study was to construct a working instrument that will help the $\mathrm{HC}$ speech therapist in management and family orientation of adult patients with dysphagia and validate this instrument in appearance and content.

\section{Guidelines in orientation manual preparation}

The preparation of "Guidance manual for Adult Patients with Dysphagia in home care" aims to facilitate the professionals work and improve the assistance quality they provide. Its guidelines add knowledge in health educationarea and also indicate strategies that help patient to adopt behaviors for a healthier experience while in treatment and recovery. Guidance for self-care and health promotion exceed the limits of mere information and adds responsibility notions about care practical application. Presently, the formulation and execution of quality improvement projects are both part of health professionals' routine and also a legal obligation in several countries of the world such as United States of America and Canada ${ }^{9}$, however, apart from the approach defined by the manual in evidence, it is understood that an educational manual is a therapeutic support strategy, for its guidelines and indications of activities to assist the patient in state of illness.

The creation of this manual intended to provide guidance to patients in dysphagia treatment, their family members and caregivers, and also to promote knowledge of what is normal throughout the procedure and possible complications as soon as give security to the patients in order to face this new stage of their life ${ }^{10}$. 
In health, the validity concept is described as the degree in which an instrument is adequate to measure what is to be measured. When an instrument turns to validation, attention seeks its purpose, goals, attributes and qualities. The content validation is an essential step in the development of new measures, because it represents the beginning of mechanisms associating abstract concepts to observable and measurable indicators. In order to perform a given measurement, the validation is related to the accuracy and purpose of the application. Validate is a term that defines the appropriate degree to measure the true value of what it is intended to measure making possible to infer how much the results were obtained through the use of the instrument ${ }^{11}$.

In order to validate measurement instruments, the most known techniques are: content validity; appearance validity; criterion validity and construct validity. The content validity seeks to investigate the representativeness of the items that reflects this content. It is content validation which defines if the instrument under analysis presents, effectively, the measuring requirements for what is being investigated ${ }^{12}$. The results are significant because of their usefulness for the desired measurement.

Validation process is based on judgment and, to that end, it is invited a group of judges or experts with proven experience in the content area of the manual. Judges have to analyze each item, establishing comprehensiveness, representation and effectiveness, and indicate the evidence regarding each item content and its relation to the measured theme ${ }^{13}$.

Regarding the appearance validation, although it is considered a strategy with subjective appreciation technique and without sophistication, it is important, since it establishes judgment about the relevance and adequacy of the content items. The judgment quantification by specialists allows to consider the comprehensiveness of the items, the representativeness of the content and its relation to what we want to measure ${ }^{14}$.

\section{METHODS}

This research consists of a cross-sectional qualitative-quantitative study. It was approved by the Research Ethics Committee of the Paraná Institute of Otorhinolaryngology Hospital - HIPO, under No. 937570 on $01 / 26 / 2015$. The research presents deep understanding potential,regarding different problems that it approaches. It consists of three steps: preparation of the manual; expert judges selection; caregiver judges selection.

The first step of the manual construction was a text with 27 pages, composed by: cover, back cover, presentation, and ten items addressed to the caregiver's orientation of patients with dysphagia hospitalized under home care. Topics: "What is home care?"; "Dysphagia and its concept"; "Oral hygiene"; "How can the speech therapist help them?"; "How to avoid risk of choking during food supply?"; "Materials that may assist the meal"; "Customer Service Team"; "Phonological monitoring based on the FOIS scale" and "Suggestions on diets and dishes presentation".

In the second step, an invitation was made to 08 speech therapists, masters or doctors working in the area of dysphagia with $\mathrm{HC}$ experience. The number of specialists was made by following the guidance of Padovani ${ }^{14}$. The contact in order to formalize and schedule the invitation was individualized, with the manual delivery and explanation on completing the questionnaire. The period of seven days for the return of the informed consent was established, and Questionnaire 1, constituted as follows: PART I - identification and PART II - Validation of appearance and content Objectives; Structure; Relevance. During this period, each professional read and completed the suggested analysis questionnaire and returned it.

Speech therapists' judges presented the following characteristics: $(75 \%)$ of them are aged between 30 and 49 years, (50\%) with training for more than 10 years, being ( $87.5 \%)$ masters; all working in HC. Time of experience in dysphagia, (37.5\%) have worked less than 5 years $(37.5 \%)$ more than ten years.

In the third step the caregivers were invited. They were chosen by their researcher's work with patients with instrumental diagnosis of dysphagia during the phono audiological therapy period. Eight caregivers of home care patients were invited; the specific characteristic of choice was patients at the beginning of the oral feeding offer of some consistency and / or with adapted consistency. Caregivers had guidance on the manual and its guidelines, depending on the needs of patients under their care.

It was established 18 days for them to return their experiences, with the following organization: PART I identification and knowledge and PART II - Validation of appearance and content. Objectives; Structure; Relevance; Writing style; Appearance; Motivation. After this period, 8 caregiverswho were included in the research gave their feedback. It is mentioned that the 
judges function consisted to write down their choice in the listed items of the questionnaire, according to the factor they judged appropriate for each item.

\section{RESULTS}

The result of the research among judges, in order to experience the process of validating the appearance and content of the elaborated manual, is based on evidences and needs observed by the speech therapist in the home care practice. It was observed that the validation of the project guidance manual allows the identification of aspects that can be improved, within the legality and validity of appearance and content. The results evaluation is based on the questionnaires answers and on the estimation of Pearson linear correlation, with scores of the variables obtained. The measurement criterion depends on the objectives and use. The valuation interpretation of Pearson linear method establishes the index of 0.6 as a parameter of strong linear correlation ${ }^{15}$. The literature findings were used to evaluate the manual regarding the validation of appearance and content.

The caregiver judges presented the following characteristics: $(50 \%)$ of them are aged between $30-49$ years. All are female (62.5\%) with complete high school education. Regarding training, (87.5\%) declared that they did not have any courses or care experience in patients with dysphagia. (87.5\%) with some degree of kinship. (50\%) are married. Among them, (75\%) dedicate themselves totally, 24 hours a day, to patient care, while $62.5 \%$ dedicate themselves to the care of the patient between 1 and 5 years.

\section{DISCUSSION}

The guidance manual used in adult patients with dysphagia in HC Speech Therapy is part of the rehabilitation process while the patient is under speech therapy monitoring and in the reintroducing process of oral diet of some consistency. The material is not expected to be applied without speech therapist accompaniment, since it is used to monitor the results obtained in therapies, and the evolution of each patient according to the FOIS scale can be documented and measured in the material. The manual must be seen as a complementary tool for therapeutic process of dysphagia rehabilitation, as a support and important guidelines on safefood supply, since caregivers in general do not have adequate knowledge for such practice with their patients.

The judging of the expert judges made it possible to improve the instrument with changes suggestions for the pilot project, that were followed. In oral hygiene, step by step images and guidelines were added. For the attending staff, it was suggested to improve the writing visualization. In speech therapy monitoring subject, it was suggested to write a brief report about it. The caregiver judges' evaluation demonstrated that the manual was considered totally suitable. Its elaboration contributes to the necessary information in dysphagic patients care in home care. The scores show a high degree of agreement, with $83 \%$ approval to fully adequate. 
Table 1. Percentage agreement indices according to content evaluation of Speech-Language Pathologists

\begin{tabular}{|c|c|c|}
\hline $\begin{array}{l}\text { GROUP OF } \\
\text { ITEMS }\end{array}$ & ITEMS & $\begin{array}{l}\text { AGREEMENT } \\
\text { INDEX }\end{array}$ \\
\hline \multirow{5}{*}{ Objectives } & 1.1 They are consistent with the needs of patients with dysphagia. & 0.87 \\
\hline & 1.2 They are consistent from the point of view of the rehabilitation process. & 0.75 \\
\hline & 1.3 Promotes behavior change and attitude. & 1.00 \\
\hline & 1.4 It may circulate in the scientific setting in the area of dysphagia. & 0.75 \\
\hline & 1.5 It meets the objectives of institutions working with dysphagic patients in home care. & 0.87 \\
\hline \multirow{12}{*}{ Structure } & 2.1 The guidance manual is suitable for caregivers / dysphagia patients in home care. & 1.00 \\
\hline & 2.2 The messages are presented in a clear and objective way. & 1.00 \\
\hline & 2.3 The information presented is scientifically correct. & 1.00 \\
\hline & 2.4 The manual is appropriate to the socio - cultural level of the proposed target audience. & 0.87 \\
\hline & 2.5 Logical sequence of the proposed content. & 0.75 \\
\hline & 2.6 The information is well structured in agreement and spelling. & 0.87 \\
\hline & 2.7 The style of writing corresponds to the level of knowledge of the target audience. & 0.75 \\
\hline & 2.8 Information and presentation are consistent. & 1.00 \\
\hline & 2.9 The size of the title and topics is adequate. & 1.00 \\
\hline & 2.10 The illustrations are expressive and sufficient. & 0.62 \\
\hline & 2.11 The material (paper, printing) is appropriate. & 1.00 \\
\hline & 2.12 Pages number is adequate. & 1.00 \\
\hline \multirow{5}{*}{ Relevance } & 3.1 The themes portray key aspects that must be reinforced. & 1.00 \\
\hline & 3.2 The material allows learning in the context of home care. & 1.00 \\
\hline & 3.3 The manual proposes to the learner to acquire knowledge in dysphagia. & 1.00 \\
\hline & 3.4 The manual approaches the necessary issues for attention, care and monitoring of dysphagia. & 1.00 \\
\hline & $3.5 \mathrm{It}$ is suitable for use by the speech therapist as a complement to their work in the context of home care. & 0.87 \\
\hline
\end{tabular}

Source: Research data.

Table 1 shows that the percentages of agreement of appearance and content evaluation of speech therapists' judges, both in their objectives and in structure and relevance, under the parameters of interpretation of Pearson correlation, reached a strong linear correlation.

Table 2. Results of the scores obtained by speech therapists

\begin{tabular}{|c|c|c|c|c|c|c|}
\hline \multirow{2}{*}{ DOMAINS } & \multirow{2}{*}{ ITEM } & \multirow{2}{*}{ N } & \multicolumn{4}{|c|}{ SCORES } \\
\hline & & & TA & A & PA & I \\
\hline \multirow{5}{*}{ Objective } & 1.1 They are consistent with the needs of patients with dysphagia. & 8 & 2 & 5 & 1 & - \\
\hline & 1.2 They are consistent from the point of view of the rehabilitation process. & 8 & 4 & 2 & 2 & - \\
\hline & 1.3 Promotes behavior change and attitude. & 8 & 6 & 2 & - & - \\
\hline & 1.4 It may circulate in the scientific setting in the area of dysphagia. & 8 & 4 & 2 & 2 & - \\
\hline & 1.5 It meets the objectives of institutions working with dysphagic patients in home care. & 8 & 4 & 3 & 1 & - \\
\hline \multirow{12}{*}{ Structure } & 2.1 The guidance manual is suitable for caregivers / dysphagia patients in home care. & 8 & 5 & 3 & - & - \\
\hline & 2.2 The messages are presented in a clear and objective way. & 8 & 4 & 4 & - & - \\
\hline & 2.3 The information presented is scientifically correct. & 8 & 3 & 5 & - & - \\
\hline & 2.4 The manual is appropriate to the socio - cultural level of the proposed target audience. & 8 & 4 & 3 & 1 & - \\
\hline & 2.5 Logical sequence of the proposed content. & 8 & 3 & 3 & 2 & - \\
\hline & 2.6 The information is well structured in agreement and spelling. & 8 & 5 & 2 & 1 & - \\
\hline & 2.7 The style of writing corresponds to the level of knowledge of the target audience. & 8 & 3 & 3 & 2 & - \\
\hline & 2.8 Information and presentation are consistent. & 8 & 6 & 2 & - & - \\
\hline & 2.9 The size of the title and topics is adequate. & 8 & 5 & 3 & - & - \\
\hline & 2.10 The illustrations are expressive and sufficient. & 8 & 1 & 4 & 2 & 1 \\
\hline & 2.11 The material (paper, printing) is appropriate. & 8 & 6 & 2 & - & - \\
\hline & 2.12 Pages number is adequate. & 8 & 5 & 3 & - & - \\
\hline
\end{tabular}




\begin{tabular}{|c|c|c|c|c|c|c|}
\hline \multirow{2}{*}{ DOMAINS } & \multirow{2}{*}{ ITEM } & \multirow{2}{*}{$\mathrm{N}$} & \multicolumn{4}{|c|}{ SCORES } \\
\hline & & & TA & A & PA & I \\
\hline \multirow{6}{*}{ Relevance } & 3.1 The themes portray key aspects that must be reinforced. & 8 & 5 & 3 & - & - \\
\hline & 3.2 The material allows learning in the context of home care. & 8 & 6 & 2 & - & - \\
\hline & 3.3 The manual proposes to the learner to acquire knowledge in dysphagia. & 8 & 5 & 3 & - & - \\
\hline & $\begin{array}{l}\text { 3.4 The manual approaches the necessary issues for attention, care and monitoring of } \\
\text { dysphagia. }\end{array}$ & 8 & 5 & 3 & - & - \\
\hline & $\begin{array}{l}3.5 \text { It is suitable for use by the speech therapist as a complement to their work in the } \\
\text { context of home care. }\end{array}$ & 8 & 4 & 3 & 1 & - \\
\hline & TOTAL & - & 95 & 65 & 15 & 1 \\
\hline
\end{tabular}

Source: Research data.

Note: For the evaluation, the categories of responses were considered: TA: totally adequate; A: Appropriate; PA: Partially Appropriate; and I: Inadequate.

This approval is consistent with the findings of the studies carried out with caregivers of patients with neurogenic dysphagia and observed that they had little knowledge about food care, requiring specific speechlanguage pathological guidance ${ }^{15}$. It is fundamental the incentive and information from the professional and health team to caregivers and family, in order to get used to limitations that they will face in the daily coexistence with the incapacitated individual. Some cares can avoid major complications and need to be practiced and repeated every meal. The caregiver motivation in following recommendations given by the speech therapist, the main dysphagia rehabilitator, are factors that determine the prognosis of oral rehabilitation ${ }^{16}$. Continuing education is based on training promotion of caregiver or patient as a major rehabilitation instrument, aiming the individual's motor functional independence. It uses dysphagia education guidelines and programs ${ }^{17}$. Teaching is primordial, since the caregiver needs adequate knowledge to take care of the patients, which reinforces the need for specific guidelines in the caregivers' preparation. This guidance values the availability of a specific manual that can guide caregivers, family members and patients, with greater knowledge, as the facilitator of specific care, and the best $\mathrm{QV}$ of $\mathrm{HC}$ patient.

Table 3. Percentage agreement indices according to the content evaluation of the caregiver judges

\begin{tabular}{|c|c|c|}
\hline $\begin{array}{l}\text { GROUP OF ITEMS } \\
\text { (DOMAINS) }\end{array}$ & ITEMS & $\begin{array}{l}\text { AGREEMENT } \\
\text { INDEX }\end{array}$ \\
\hline \multirow{3}{*}{ Objective } & 1.1 It meets the objectives of guiding patients with dysphagia. & 1.00 \\
\hline & 1.2 Help during the rehabilitation process. & 1.00 \\
\hline & 1.3 It is suitable for use by the caregiver of the patient with dysphagia. & 1.00 \\
\hline \multirow{7}{*}{ Structure } & 2.1 Is the cover attractive? It Indicates the content of the material? & 1.00 \\
\hline & 2.2 The size of the title and the content in the topics is suitable & 1.00 \\
\hline & 2.3 Topics have sequence & 1.00 \\
\hline & 2.4 Information and presentation are consistent & 1.00 \\
\hline & 2.5 Pages number is adequate & 1.00 \\
\hline & 2.6 The material (paper, printing) is appropriate & 1.00 \\
\hline & 2.7 Themes depict important key aspects & 1.00 \\
\hline \multirow{6}{*}{ Writing Style } & 3.1 Writing is in proper style & 1.00 \\
\hline & 3.2 The text is interesting & 1.00 \\
\hline & 3.3 Vocabulary is accessible & 1.00 \\
\hline & 3.4 There is an association of the theme of each session with the corresponding text & 1.00 \\
\hline & 3.5 The text is clear & 1.00 \\
\hline & 3.6 The writing style corresponds to the level of knowledge of the target audience & 1.00 \\
\hline \multirow{4}{*}{ Appearance } & 4.1 Pages or sections appear organized & 1.00 \\
\hline & 4,2 The illustrations are simple (preferably drawings) & 1.00 \\
\hline & 4.3 The illustrations serve to complement the texts & 1.00 \\
\hline & 4.4 The illustrations are expressive and sufficient & 1.00 \\
\hline
\end{tabular}




\begin{tabular}{llc}
\hline $\begin{array}{c}\text { GROUP OF ITEMS } \\
\text { (DOMAINS) }\end{array}$ & \multicolumn{1}{c}{ ITEMS } & $\begin{array}{c}\text { AGREEMENT } \\
\text { INDEX }\end{array}$ \\
\hline & $\begin{array}{l}\text { 5.1 The material is appropriate for age, gender and culture. } \\
\text { 5.2 The material presents logic }\end{array}$ & 1.00 \\
& 5.3 The interaction is invited by the texts. Suggests actions & 1.00 \\
Motivation & 5.4 The manual approaches the necessary issues for patient with dysphagia care & 1.00 \\
& 5.5 Promotes behavior and attitude change & 1.00 \\
& 5.6 The manual proposes to the learner to acquire knowledge to perform care related to dysphagia & 1.00 \\
\hline
\end{tabular}

Source: Research data.

The appreciation of caregivers judges to the evaluation process of appearance and content, presented in Table 3, when compared to objectives, structure, writing style, appearance and motivation, showed concordance index 1 for all questions, which means a very strong correlation under the parameters of Pearson's correlation interpretation.

Table 4. Results of the scores obtained by the judges analysis of the questionnaire for the caregiver

\begin{tabular}{|c|c|c|c|c|c|c|}
\hline \multirow{2}{*}{ DOMAINS } & \multirow{2}{*}{ ITEM } & \multirow{2}{*}{$\mathbf{N}$} & \multicolumn{4}{|c|}{ SCORES } \\
\hline & & & TA & A & PA & I \\
\hline \multirow{3}{*}{ Objective } & 1.1 It meets the objectives of guiding patients with dysphagia. & 8 & 8 & - & - & - \\
\hline & 1.2 Help during the rehabilitation process. & 8 & 7 & 1 & - & - \\
\hline & 1.3 It is suitable for use by the caregiver of the patient with dysphagia. & 8 & 8 & - & - & - \\
\hline \multirow{7}{*}{ Structure } & 2.1 Is the cover attractive? Does it Indicate the content of the material? & 8 & 5 & 3 & - & - \\
\hline & 2.2 The size of the title and the content in the topics is suitable & 8 & 8 & - & - & - \\
\hline & 2.3 Topics have sequence & 8 & 8 & - & - & - \\
\hline & 2.4 Information and presentation are consistent & 8 & 6 & 2 & - & - \\
\hline & 2.5 Pages number is adequate & 8 & 8 & - & - & - \\
\hline & 2.6 The material (paper, printing) is appropriate & 8 & 4 & 4 & - & - \\
\hline & 2.7 Themes depict important key aspects & 8 & 7 & 1 & - & - \\
\hline \multirow{6}{*}{ Writing Style } & 3.1 Writing is in proper style & 8 & 4 & 4 & - & - \\
\hline & 3.2 The text is interesting & 8 & 6 & 2 & - & - \\
\hline & 3.3 Vocabulary is accessible & 8 & 5 & 3 & - & - \\
\hline & 3.4 There is an association of the theme of each session with the corresponding text & 8 & 8 & - & - & - \\
\hline & 3.5 The text is clear & 8 & 7 & 1 & - & - \\
\hline & 3.6 The writing style corresponds to the level of knowledge of the target audience & 8 & 6 & 2 & - & - \\
\hline \multirow{4}{*}{ Appearance } & 4.1 Pages or sections appear organized & 8 & 7 & 1 & - & - \\
\hline & 4,2 The illustrations are simple (preferably drawings) & 8 & 4 & 4 & - & - \\
\hline & 4.3 The illustrations serve to complement the texts & 8 & 6 & 2 & - & - \\
\hline & 4.4 The illustrations are expressive and sufficient & 8 & 4 & 4 & - & - \\
\hline \multirow{7}{*}{ Motivation } & 5.1 The material is appropriate for age, gender and culture. & 8 & 8 & - & - & - \\
\hline & 5.2 The material presents logic & 8 & 8 & - & - & - \\
\hline & 5.3 The interaction is invited by the texts. Suggests actions & 8 & 7 & 1 & - & - \\
\hline & 5.4 The manual approaches the necessary issues for patient with dysphagia care & 8 & 8 & - & - & - \\
\hline & 5.5 Promotes behavior and attitudechange & 8 & 8 & - & - & - \\
\hline & $\begin{array}{l}5.6 \text { The manual proposes to the learner to acquire knowledge to perform care related to } \\
\text { dysphagia }\end{array}$ & 8 & 8 & - & - & - \\
\hline & TOTAL & - & 173 & 35 & - & - \\
\hline
\end{tabular}

Source: Research data.

Note: For the evaluation, the categories of responses were considered: TA: totally adequate; A: Appropriate; PA: Partially Appropriate; and I: Inadequate. 


\section{CONCLUSION}

At the end of the research, it is possible to declare the importance of the manual and the actions carried out regarding the validation of appearance and content, since they serve as an effective help for caregivers of dysphagic patients in home care treatment, even when they are not directly trained on necessary techniques to promote better quality of life of patients under their care. In accordance with the findings in the mentioned literature, and in view of the favorable results achieved in the research, it may be suggested that its application can be consolidated with greater amplitude, to test and confirm its sensitivity and specificity, as well as its validity.

\section{REFERENCES}

1. Carvalhais M, Sousa L. Qualidade dos cuidados domiciliares em enfermagem a idosos dependentes. Saúde Soc. 2013;22(1):160-72.

2. Albuquerque AG, Oliveira GSM, Silva VL, Nascimento CB. Capacidade funcional e linguagem de idosos não-participantes e participantes de grupos de intervenção multidisciplinar na atenção primária à saúde. Rev. CEFAC [online]. 2012 [acesso em: 20 abril 2015]; 14(5):952-62. Disponível em: http://dx.doi.org/10.1590/ S1516-18462012005000019.

3. Garcia RSF. A história do home care no Brasil. 2014. Disponível em: http://www.webartigos.com/ artigos/a-historia-do-home-care-no-brasil/120711/ \#ixzz41HqNCRC

4. Dias LV, Santos RS, Mendes JM, Willig MH. The contributions of continuing education on oropharyngeal dysphagia for pediatric nursing care at a teaching hospital. Rev. CEFAC [Internet]. 2015 Oct [cited 2018 Mar 05]; 17(5):1531-40. Available from:http://www.scielo.br/scielo.php?script $=$ sci_ arttext\&pid=S151618462015000501531\&lng=en. http://dx.doi.org/10.1590/19820216201517514.

5. CFF. Resolução CFFa. № 356, de 06 de dezembro de 2008. Dispõe sobre a competência técnica e legal do fonoaudiólogo para atuar nas disfagias orofaríngeas.

6. CFFa. Resolução CFFa. № 382 , de 20 de abril de 2010. Dispõe sobre o reconhecimento das especialidades em Fonoaudiologia Escolar/ Educacional e Disfagia pelo Conselho Federal de Fonoaudiologia, e dá outras providências. DOU. 22.04.2010.
7. Silva RG. A eficácia da reabilitação em disfagia orofaríngea. Pró-Fono R. Atual. Cientif. 2007;19(1):123-30.

8. Silvério CC, Hernandez AM, Gonçalves MIR. Ingesta oral do paciente hospitalizado com disfagia orofaríngea neurogênica. Rev. CEFAC. 2010;12(6):964-70.

9. Bellucci Júnior JA, Matsuda LM. Construção e validação de instrumento para avaliação do acolhimento com classificação de risco. Rev Bras Enferm. 2012;65(5):751-7.

10. Gozzo TO, Lopes DO, Prado MS, Cruz LAP, Almeida AM. Informações para a elaboração de um manual educativo destinado às mulheres com câncer de mama. Esc Anna Nery. 2012;6(2):306-11.

11. Morais EAS, Salomon SOR, Veiga VC. Indicadores de saúde no cuidado ao paciente crítico neurológico. Rev Rene. 2014;15(2):189-95.

12. Cerejeira R, Veloso-Teles R, Lousan N, Pinto Moura C. The Portuguese version of the Rhino QOL Questionnaire: validation and clinical application. Braz J Otorhinolaryngol. 2015;81(6):630-5.

13. Oliveira MS, Fernandes AFC, Sawada NO. Manual educativo para o autocuidado da mulher mastectomizada: um estudo de validação. Texto \& contexto enferm [serial on the Internet]. 2008 January [cited 2012 Jan 27] 17(1):115-23. Available from: http://www.scielo.br/pdf/tce/v17n1/13.pdf.

14. Padovani ARP. Protocolo fonoaudiológico da introdução e transição de alimentação por via oral para pacientes com risco para disfagia (PITA). [Dissertação] São Paulo (SP): Faculdade de Medicina da Universidade de São Paulo; 2010.

15. Barroso EM, Carvalho AL, Paiva CE, Nunes JS. Translation and cross-cultural adaptation into Brazilian Portuguese of the Vanderbilt Head and Neck Symptom Survey version 2.0 (VHNSS 2.0) for the assessment of oral symptoms in head and neck cancer patients submitted to radiotherapy. Braz J Otorhinolaryngol. 2015;81(6):622-9.

16. Vasconcelos AP. A importância do trabalho em conjunto do fonoaudiólogo e do nutricionista no atendimento ao paciente disfágico. Pró-fala. 2013. Disponível em: http://www.profala.com/arttf159.htm

17. Hirata GC, Santos RS. Reabilitação da disfagia orofaríngea em crianças com paralisia cerebral: uma revisão sistemática da abordagem fonoaudiológica. Int. Arch. Otorhinolaryngol. 2012;16(3):396-9. 